This item was submitted to Loughborough's Research Repository by the author.

Items in Figshare are protected by copyright, with all rights reserved, unless otherwise indicated.

\title{
Working together: library value at the University of Nottingham
}

\section{PLEASE CITE THE PUBLISHED VERSION}

http://dx.doi.org/10.1108/PMM-03-2014-0011

\section{PUBLISHER}

(C) Emerald Group Publishing Ltd.

\section{VERSION}

AM (Accepted Manuscript)

\section{PUBLISHER STATEMENT}

This work is made available according to the conditions of the Creative Commons Attribution-NonCommercialNoDerivatives 4.0 International (CC BY-NC-ND 4.0) licence. Full details of this licence are available at: https://creativecommons.org/licenses/by-nc-nd/4.0/

\section{LICENCE}

CC BY-NC-ND 4.0

\section{REPOSITORY RECORD}

Creaser, Claire, Susanne Cullen, Ruth Curtis, Nicola Darlington, Jane Maltby, Elizabeth Newall, and Valerie C.L. Spezi. 2019. "Working Together: Library Value at the University of Nottingham". figshare. https://hdl.handle.net/2134/17779. 
Title

Working together: Library value at the University of Nottingham

\section{Introduction}

In 2012, two projects concerning the value of libraries to teaching and research staff were conducted simultaneously. These were Working together: evolving value for academic libraries (Working together, 2011) led by LISU, Loughborough University, UK and Raising Academic Impact (University of Nottingham, UK). The projects were initially unconnected: SAGE had commissioned LISU to conduct the Working Together (WT) project, whilst at the University of Nottingham (UoN), academic librarians began to investigate academic staff perceptions of library services through Raising Academic Impact (RAI).

The Working Together project was an international study investigating good practice in academic libraries' relationships with teaching and research staff in their institutions. As part of the methodology, described in Creaser \& Spezi (2012) a call for the recruitment of case studies was issued and the UoN volunteered, after recognising the similarities between the projects.

This paper presents key findings from the two studies in parallel. It is anticipated these discoveries will be of interest to the wider library community.

\section{Projects' drivers}

A common driver for both projects was the publication of a report commissioned by RLUK (Auckland, 2012), which outlined the skills sets required by academic librarians to effectively support the current and future information needs of researchers. RAI was also influenced by a separate small scale study (Cooke et al., 2011) undertaken at Loughborough University which evaluated the impact of academic librarians on part of their user community.

In preparation for an anticipated shift in the role of the academic librarian, RAI aimed to investigate how useful UoN academics found the services currently provided by their librarians in support of teaching, learning and research. At the same time SAGE expressed an interest in investigating the value of academic libraries to teaching and research staff following the publication of the ARL report (ARL, 2010) and, albeit more indirectly, the work surrounding the LibValue (n.d.) project.

\section{The 'Working together' project}

The focus of this project was to investigate the value of academic libraries for teaching and research staff. The project sought to identify both evidence of value and perceptions of the value of academic libraries, exploring the range of services offered to academics in support of their teaching and research, in order to identify elements of good practice. Outreach and communication between the library and academic departments were also explored, identifying the extent to which both units work together to ensure that library services are supporting academics effectively. 
The objective was to provide the library community with a better understanding of the connections between academic departments and libraries and to identify examples of good practice in working relationships.

Eight in-depth case studies (two in the UK, four in the US and two in Scandinavia) were conducted, followed by an online survey across all three regions. The aim of the survey was to triangulate the primary findings from the case studies and see the extent to which they resonated more widely with librarians' experiences.

\section{The RAI project}

The aim of RAI was to increase the impact of academic librarians in departments across the UoN, by:

1. assessing the extent to which academic staff were currently aware of services, support and resources;

2. identifying practical interventions to raise awareness of services and resources;

3. involving academic staff in shaping the services offered to ensure their needs were being met; and

4. ensuring academic librarians had the appropriate skills to maximise impact in academic departments.

Four key phases were planned to address these objectives, the first being a survey (including a questionnaire and focus group) undertaken primarily to assess awareness, uptake and value of existing and potential services; but also to inform the remaining three phases. The questionnaire (which included both closed and open questions) was distributed to all 2,991 teaching and research staff at the UoN in March 2012, achieving a 9\% response rate. Following questionnaire analysis, a focus group was held with four academics in order to gain a deeper understanding of certain findings.

Work was subsequently completed on the second phase of the project (to improve academic librarian web presence), however phases three and four - a programme of promotional events for academic staff and a training programme for academic librarians were suspended following the announcement of a library service restructure midway through the project. This paper focuses on results from the first phase.

\section{Evidence and perceptions of value}

Determining the value of academic libraries to academic staff proved extremely difficult, as little evidence beyond the occasional anecdotal piece is being collected. While institutions are aware of the need to gather evidence, with most beginning to do this, the WT case studies showed there is no systematic collection of evidence of value; nor is the impact of services provided to teaching and research staff assessed. The research team therefore turned its attention to perceptions of value, i.e. how value is perceived by libraries themselves and by academic staff.

The findings indicated some variation in perception. Overall, there was considerable librarian concern that academics did not value librarians because they did not understand 
or appreciate what the latter group already did or what services could be offered to both academics and students, with comments such as "Staff never cease to be amazed at what we can actually provide/help them with (UK librarian). Academic staff interviewed were divided; some confirmed the librarians' belief about the lack of awareness of services - "I'm not sure that the faculty as a whole appreciate what librarians do or understand what they do" (UK academic) - but there were others who appreciated the 'helpfulness' of the library "I feel confident that if I need something ... I know that I can contact them and get help" (Scandinavian academic).

Similar findings emerged from the RAI survey; a key undertaking of which was to explore academic staff perceptions of the value of existing services, support and resources. Open comments received on the questionnaire demonstrated that some academics were unaware of all their librarians could do to support them; whilst others were appreciative of the 'specialist' and 'invaluable' support they received.

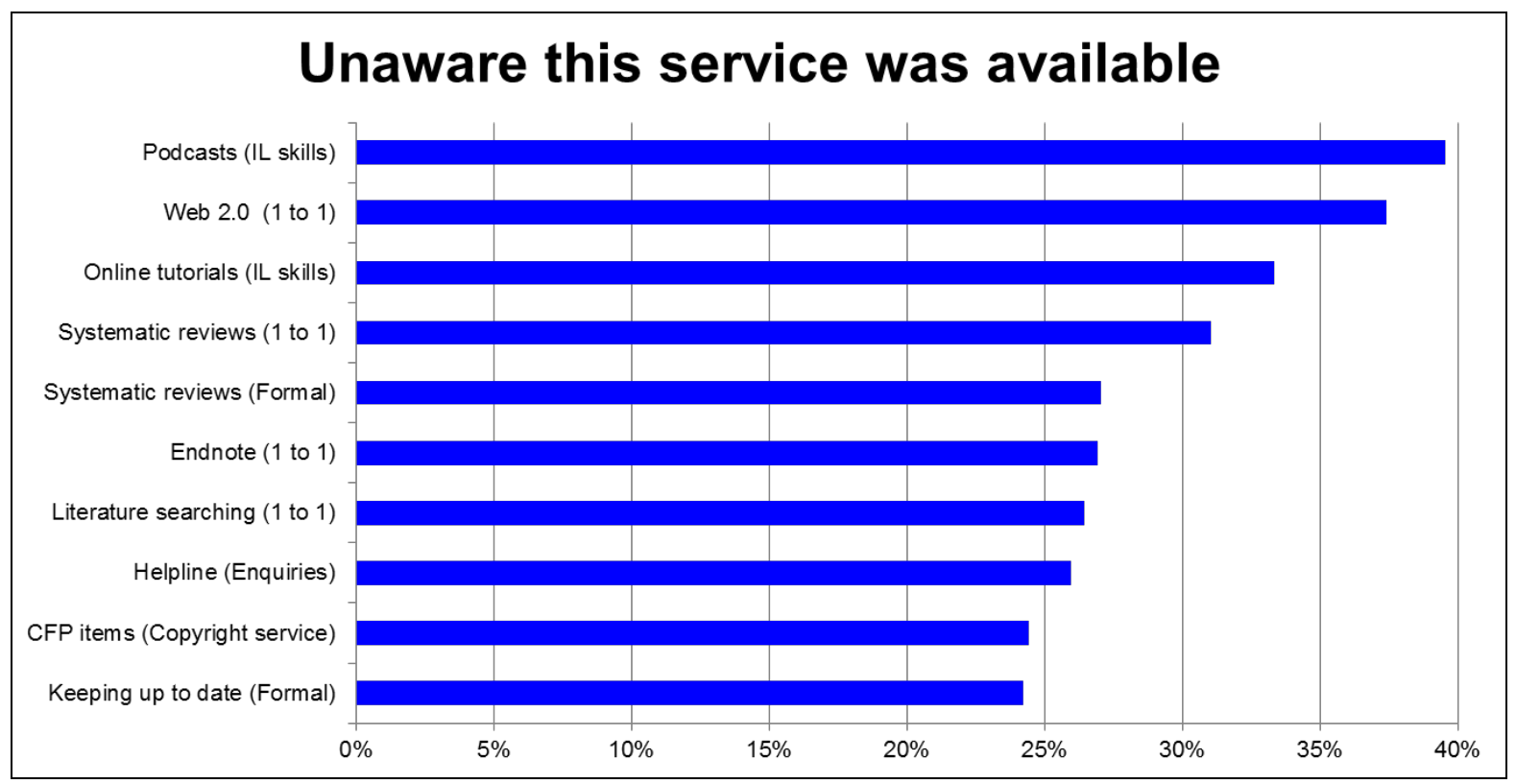

Figure 1: Unaware this service was available (RAI survey) (IL = Information Literacy)

Figure 1 identifies the top ten existing services (out of 20) of which academics were unaware, including information literacy (IL) skills teaching for students through eLearning (podcasts and online tutorials); and one-to-one support/formal training for academics themselves (e.g. systematic reviews, Endnote). These findings highlighted a clear need for improved marketing and communication amongst UoN academic librarians to promote certain areas.

In terms of ascertaining specific values placed on existing services, RAI questionnaire respondents were asked to provide a rating of very useful, quite useful, not very useful or not at all useful for each service. Figure 2 identifies the top ten services (out of 20) rated as either very or quite useful overall by academics. All are related to what could be termed as traditional library services - reading lists (ensuring currency and the availability of recommended texts/scanned items); enquiries (in-person); and information skills teaching (for undergraduates, taught and research postgraduates). 


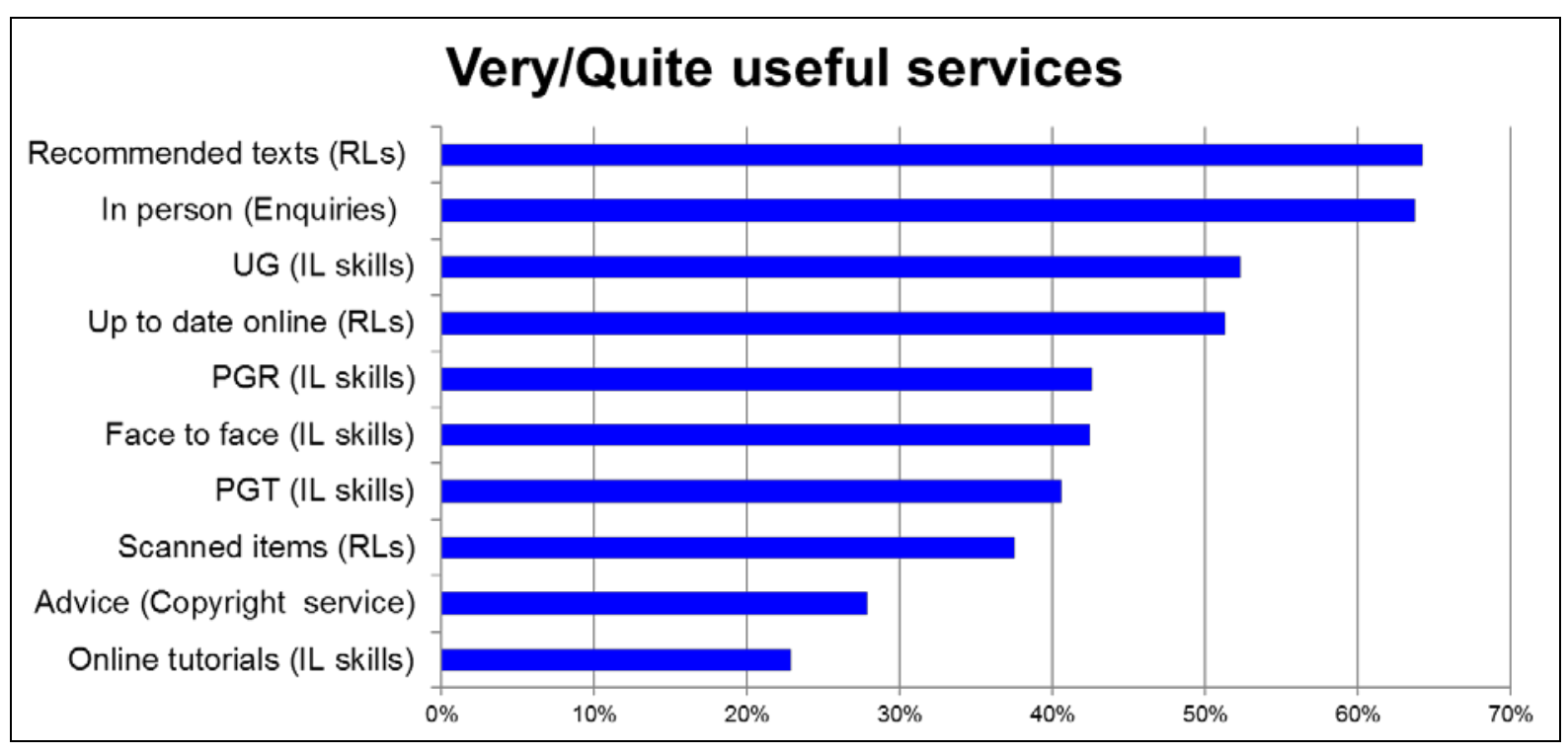

Figure 2: Very/Quite useful services (RAI survey) (RLs = Reading Lists; UG = Undergraduates; IL = Information Literacy; PGR = Research postgraduates; $\mathrm{PGT}=$ Taught postgraduates)

\section{Teaching and information literacy}

As Figure 2 highlights, teaching IL skills to students remains a highly valued library service amongst UoN academics. This is further emphasised by Figure 3, which details the top ten additional services academics would like their librarians to provide. The RAl questionnaire asked respondents to rank their top five choices from a list of 20. Responses were weighted to gain an overall view of the top ten preferred services.

As Figure 3 highlights, the top five services all relate to teaching additional skills to students:

- how to avoid plagiarism (weighted score 423);

- study skills (weighted score 371 );

- advanced Google (weighted score 256);

- digital literacy skills (weighted score 199); and

- critical appraisal skills (weighted score 191).

RAI focus group feedback supported these findings, with participants welcoming a move to librarians teaching study skills, critical appraisal and avoiding plagiarism in addition to more traditional IL skills teaching. 


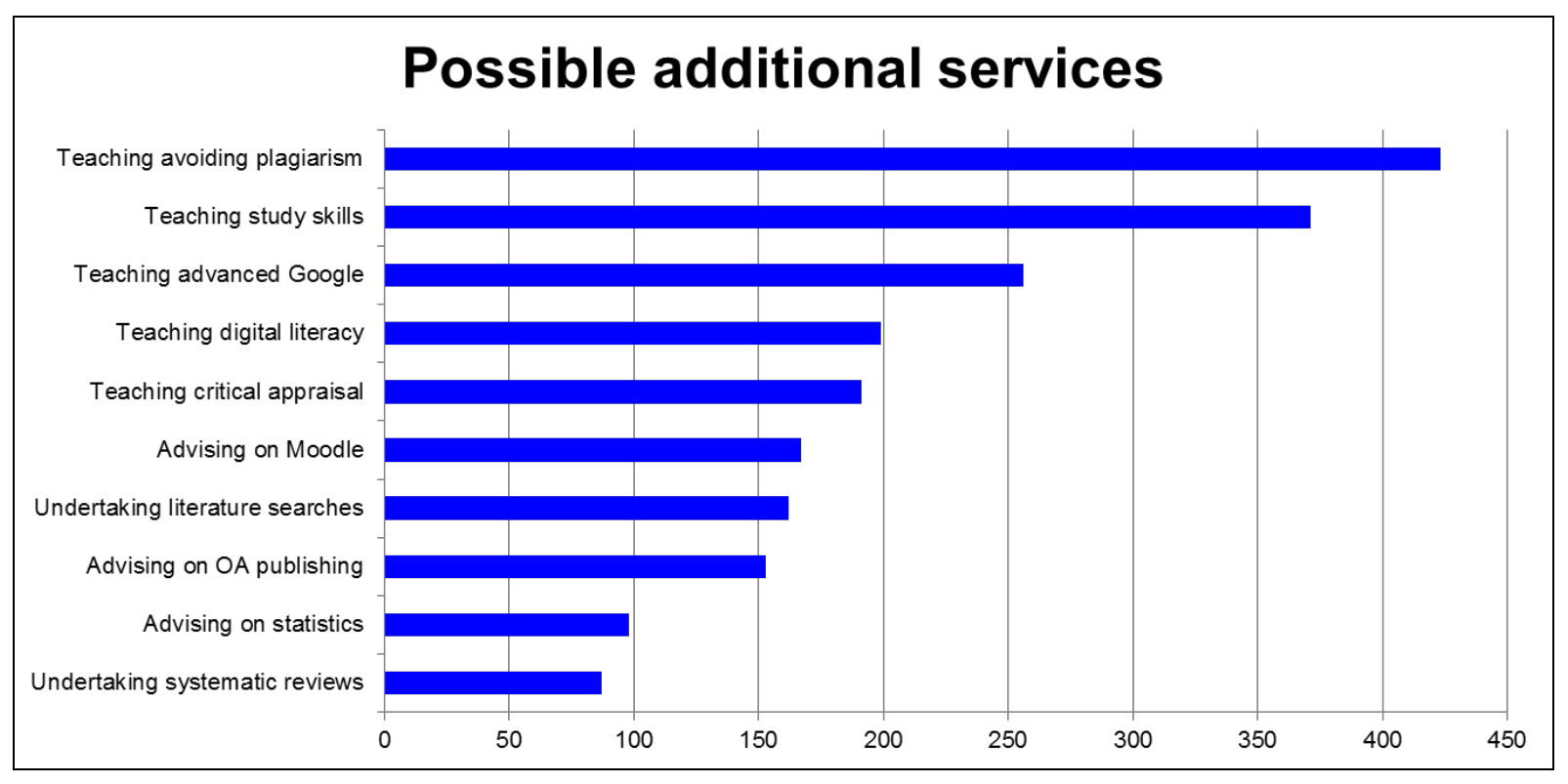

Figure 3: Possible additional services (RAI survey)

The value of IL teaching is further corroborated by the WT project, where it was shown to be a key component of the work of librarians, who were trying to embed IL into courses as much as possible. Eighty-eight per cent of librarians responding to the WT survey felt this activity was important or very important in their library. This requires collaborative work with teaching staff to design, plan and time interventions within modules; the objective being to make IL training relevant to course content and therefore to the student.

Taking embedded IL a step further, there were examples where classes are taught in partnership by both teaching staff and a librarian. This is particularly successful in vocational subjects geared towards an evidence-based approach such as nursing, physiotherapy or occupational therapy, although evidence showed this practice was not necessarily confined to these subjects. This denotes an important culture shift for librarians; no longer reacting solely to ad-hoc requests from teaching staff, they are now proactively approaching departments to embed their teaching into courses. Importantly, it was perceived that the involvement of librarians in curriculum design can make a significant difference. For example, driven by national changes to nursing education (all nurses to be educated to degree level) Nottingham developed a new course with a high level of blended learning. The health science librarian was directly involved in its design from the outset, over an 18 month development cycle, identifying relevant resources and developing information skills elements. Librarians were able to demonstrate to teaching staff how they can help at an early stage, both in terms of contributing to learning outcomes and in helping students develop IL skills and become competent practitioners.

\section{Research support}

Findings from the WT project indicate that research support for academic staff tends not to be as well developed as teaching support. Indeed, the librarians interviewed felt that more could definitely be done in this area, although they acknowledged it was generally difficult to strike the right balance between the two. Issues impeding the development of research 
support included the perceived self-sufficient image projected by academics, with librarians lacking the confidence to approach academics with offers of help. Librarians also struggle to envisage how they can help researchers in their journey because they are often unsure of the sort of support required.

Research support is very much dependant on the specific relationships librarians have established with both academic departments and individuals within them. Very few research partnerships were reported, although there was a consensus amongst librarians that this is the way forward. Those few librarian-faculty partnerships uncovered by the project included collaboration in the preparation of bids, conducting literature reviews, and co-writing articles.

Similar findings emerged from RAI. The RLUK report (Auckland, 2012) indicated a skills gap in several key areas amongst academic librarians in relation to research activities, and suggested researchers would value such support from their librarians; including advising on data management, and knowledge of sources of research funding.

However, as Figure 4 indicates, when asked to rank the top ten additional services academics would like to receive from librarians, assistance with research activities, such as assisting with grant applications and data management, and collaborating on research projects, were placed in the bottom ten, with weighted scores of less than 100.

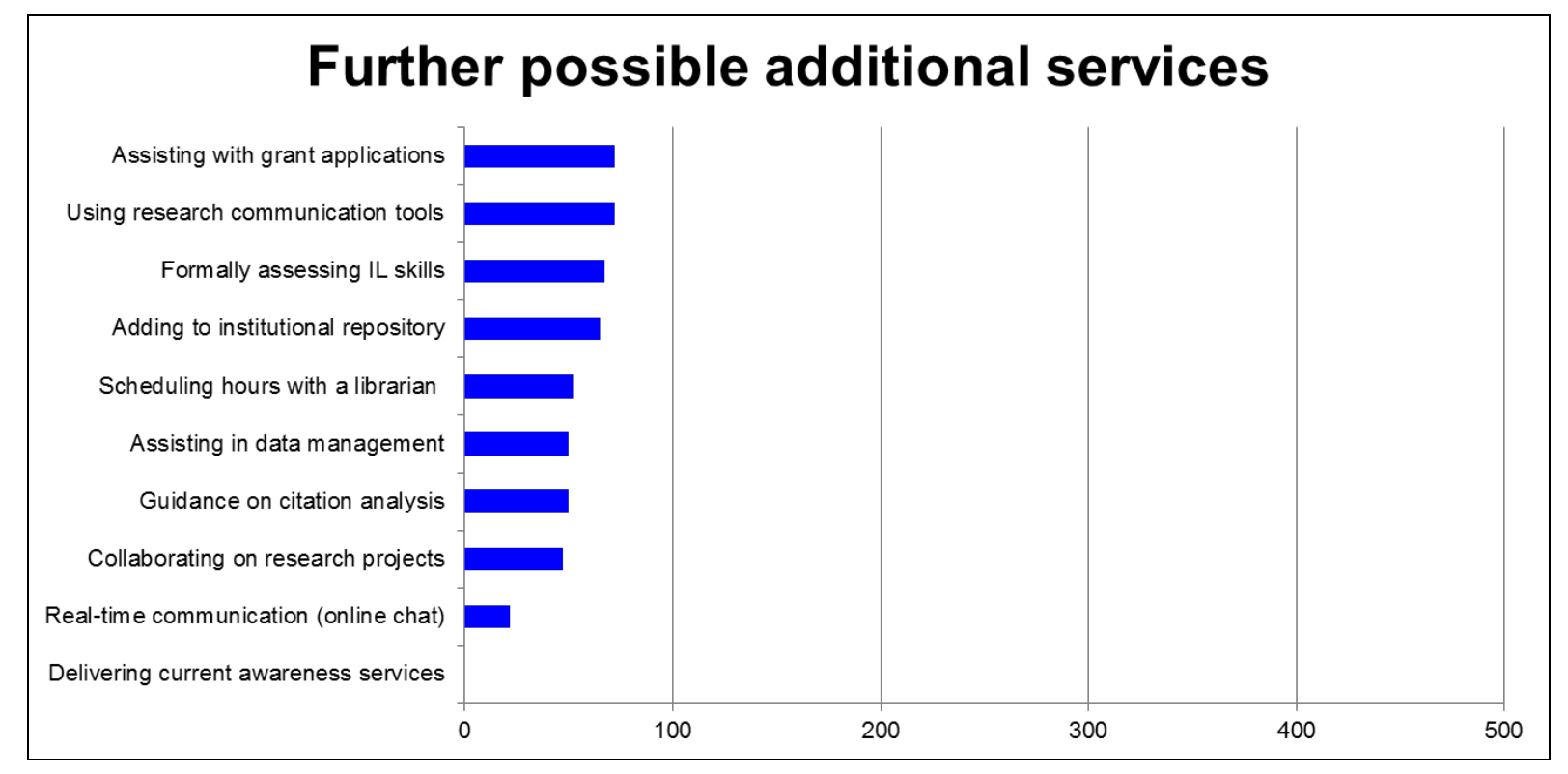

Figure 4: Further possible additional services (RAl survey)

Again, RAI focus group feedback corroborated these findings. Participants considered their research to be their own responsibility and would not think to request library collaboration. In light of the RLUK findings however, further investigation is needed in this area. Do UoN academics really not need support with research? Do they not see support for research as a valuable library service? Or, are UoN academics just unaware their librarians can help with research support?

Conducting literature searches and/or systematic reviews and advising on open access publishing were the key research activities in which academics indicated they would 
welcome library collaboration (Figure 3); again reflecting similarities with WT findings - one third of respondents to the WT librarians' survey felt that help with literature reviews was the library service most valued by research staff.

However, when exploring whether these research trends were consistent across all UoN faculties (Arts; Engineering; Medicine and Health; Science; and Social Sciences), some differences were identified. All faculties expressed a need for support with open access publishing, but conducting literature searches and/or systematic reviews appeared to be faculty-specific. This service was considered of most value in the two faculties of Medicine and Health and Science; of some value in Engineering and Social Sciences; but of least value in Arts. Previous studies have also identified trends within subject areas, suggesting approaches to research, information needs and take-up of library services differ according to discipline (Auckland, 2012; Cooke et al., 2011).

\section{Communications and marketing}

The visibility of the library was an important issue addressed by WT. Librarians understood that communication was key to promoting the value of the library, but they did not always do this effectively - '... our library is bad at marketing and advocacy so that the staff doesn't know what we can offer'. (Scandinavian librarian). This was reinforced by those primary findings indicating that academics are not always fully aware of what the library does, and as a consequence may not value the library as much as expected.

Raising awareness of services the library could provide to support academics and students, and of its contribution to the wider institution, is a key component of demonstrating library value. It does however require time and enthusiasm from library staff, not just to develop and maintain effective lines of communication but also to be able to deal with the potential increased demand which may result from this. One (US) librarian said, 'One or two bad experiences [...] and the faculty disappear forever from librarian interaction'.

Communication is a key component of library visibility. Channels are very diverse with different methods suiting different audiences and in the WT case studies there was little consensus over what worked best in different circumstances. However, it was recognised that academic departments often have different ways of doing things and librarians need a sound understanding of this in order to adapt their communications to departments. It was also recognised that faculty outreach relies on personal relationships but that it is time consuming and can get sacrificed accordingly.

Getting the library involved in university-wide events aimed at academic staff, such as conferences, festivals, author book signings/presentations or public lectures, proved beneficial in terms of faculty outreach. Informal communication with academic staff at these events promotes the library's visibility, which in turn promotes library services to staff who may be unaware of some of them.

General marketing can help raise the library's profile and is increasingly seen as an essential activity. One senior library manager noted that: "our role has evolved to marketing as well in terms of making sure that people are aware of what the library has to offer 
because it has changed so much over time that it's important to get the word out". Some libraries now have dedicated marketing teams, responsible for high-level, library-wide communications as well as helping to promote specific services, but this is far from universal.

A designated marketing role within the library can help to package the library message, to prevent over-notification and to be more strategic in communication. The WT survey did not specifically enquire about marketing, but many respondents raised it spontaneously as an issue. Poor marketing was seen as a barrier to good communication by survey respondents. Much of the communication which libraries have with users can be seen as marketing announcing new resources and services being a prime example - but using this as a label within the library can change the emphasis, and lead to a broader promotion of the library as a whole.

Language is another element of the communication and marketing strategy. Librarians must talk the language of their users. One librarian reported using the expression " $21^{\text {st }}$ century competencies" coined by one academic at their institution instead of 'information literacy' because it was felt that it was more meaningful to academics. Another example is the use of 'training' for events promoted to academics - "awareness raising" was suggested as more appropriate and conveying a more positive note. The WT findings indicated that, although some new skills for the LIS profession are highly desirable, the existing skills of librarians are still relevant today but may need re-branding to show their relevance in this modern age.

\section{Conclusions}

The WT project provided recommendations for individual librarians, library managers and university managers to help promote library value, and improve perceptions of value, among academic staff. Key amongst these was reaching out to academics to promote library skills and services using language which would resonate with these staff, rather than the traditional LIS terms; and to collect and use evidence of value at all levels in the institution. RAl reported its findings to senior management, to inform their discussions around the direction of the library and librarian roles.

Beyond the recommendations however, many of which were not unexpected (and which could be seen as tantamount to common sense), some fundamental questions remain. Why do some academics not use their libraries? Is this because the services are not required, they are inadequate, or they are not known of by academics?

Through RAI, the UoN library took the initiative of trying to address these questions. While current services were rated as very/quite useful overall, improved marketing \& promotion was required in key areas to increase awareness and demonstrate value. Librarians will need to tailor promotion of services to meet the specific requirements of academics, and develop skills and expertise in new/emerging areas.

It is likely the same issues will apply to many Higher Education institutions and therefore there is more research, promotion, and training to be conducted. 
Acknowledgement:

The authors would like to acknowledge the contribution of SAGE, who funded the Working Together research.

\section{References}

Association of College and Research Libraries. Value of Academic Libraries: A Comprehensive Research Review and Report. Researched by Megan Oakleaf. Association of College and Research Libraries, Chicago, available at:

www.ala.org/acrl/sites/ala.org.acr/files/content/issues/value/val report.pdf (accessed 6 September 2013)

Auckland, M. (2012), Re-skilling for research: an investigation into the role and skills of subject and liaison librarians required to effectively support the evolving information needs of researchers, Research Libraries UK, London, available at: www.rluk.ac.uk/files/RLUK\%20Re-skilling.pdf (accessed 13 September 2013)

Creaser, C. and Spezi, V. (2013), "Improving perceptions of value to teaching and research staff: The next challenge for academic libraries", Journal of Librarianship and Information Science, Published online before print May 15, 2013, available at: http://lis.sagepub.com/content/early/2013/05/08/0961000613477678.full (accessed 13 September 2013)

Cooke, L., Norris, M., Busby, N., Page, T., Franklin, G., Gadd, E. and Young, H. (2011), "Evaluating the impact of Academic Liaison Librarians on their user community: A review and case study", New Review of Academic Librarianship, Vol. 17 No. 1, pp. 5-30

LibValue: value, outcomes, and Return on Investment of Academic libraries (no date). Available at: http://libvalue.cci.utk.edu (accessed 13 September 2013)

Working together: evolving value for academic libraries, 2011. Available at: http://libraryvalue.wordpress.com/ (accessed 13 September 2013) 